\title{
Tanrı Algısı Ölçeği (TA): Geçerlik ve Güvenirlik Çalışması
}

\author{
ÖZLEM GÜLER \\ UZM. PSK., ANKARA Ü. SOSYAL BILIMLER ENSTITÜSÜ \\ e-posta: aramissis@hotmail.com
}

\begin{abstract}
God Perception Scale: Its Validity and Reliabilty. Purpose of this study was to analize validity and reliability of God Perception Scale for measure individual' s God perceptions. So, the researcher first formed a pool of 32 items and then adminestered them to 535 subjects whose ages ranged from 20 and 60 in six different cities, Bursa, Ankara, Erzincan, İstanbul, Silifke and Samsun. We analised data with the help of item-total correlations, Cronbach-alfa, factor analysis and several methods. Cronbach Alpha coefficient of GP was, 83. Factor analysis showed that there were five factors in the scale. The analyses revealed that "God Perception Scale" is a reliable and valid instrument.
\end{abstract}

\section{key words}

God Perception, God Perception Scale, Validity, Reliability

\section{A. GiRiş}

Tanrı algısı, bireyin Tanrı'ya yönelik tüm atıfları, duygu ve düşünceleridir. Tanrı hakkında bir bilgisi olan her bireyin zihninde bir Tanrı imgesi oluşur ve aslında Tanrı'nın varlığına inanan veya inanmayan her insanın zihninde Tanrı ile ilgili bir şemanın olduğu düşünülebilir.

İnanan bir birey için inandıkları, onun yaşam şeklini etkileyebilmektedir. Allport'a ${ }^{1}$ göre, çok güçlü bir inanç insanın ruhsal ve fiziksel sağlı̆̆ını derinden etkilemektedir. İnanan birey için inancının merkezinde Tanrı olduğu için bireyin Tanrı'yı nasıl algıladığı önemli bir konudur.

1 Allport, G.; (1950). Individual and His Religion: A Psychological Interpretation, New York: The Macmillan Company. 
Tanrı algısı, çocuklukta oluşmaya başlayan, bireyin çevresi, dini ve kişiliği tarafından şekillenen bir yapıdır. Tanrı algısı oluşurken bireye öğretilen dini temsiller o bireyin Tanrı'ya yönelik algısının olumlu veya olumsuz yönde gelişmesini etkileyebilir. Bir dine inanan kişi, o dinin Tanrı tasavvurundan etkilenerek bir Tanrı imgesi geliştirebilir. Birey, Tanrı'ya ilişkin duygu ve düşünceleri ile de kendine özgü bir tasavvura sahip olur. Yapıcı'ya göre ${ }^{2}$, Tanrı inancında dini duygu gelişimi önemlidir ve Tanrı inancı, kişinin kendi dini eğilimleri ve kutsal olana bağlanma isteğinin farkına varması ile oluşur. Yine Tanrı kavramı kişinin sosyal-kültürel çevresinden, aldığı eğitimden ve içsel yaşantılarından etkilenmektedir.

Tanrı algısı konusunda önemli bir çalışma Benson ve Spilka tarafından yapılmıştır ${ }^{3}$. Bilişsel tutarlılık teorisine dayanarak, benlik imgesinin Tanrı imgesi üzerinde belirleyici bir etken olduğunu ileri sürmüsslerdir. Tutarlılık teorisine göre; kişinin genel benlik algısına uymayan bir bilgi bilişsel bir uyumsuzluk yaratır. Böyle bir uyumsuzluğun neden olduğu rahatsızlıkla birey, bu huzursuzluğu azaltmak ve benlik imgesi ile tutarlı bir bilgiyi sağlamak için inkar, çarpıtma veya seçici algılama gibi teknikler kullanabilir. Tanrı imgesine dayanan tutarlılık teorisine göre bireyin benlik imgesi Tanrı imgesini belirler ${ }^{4}$. Benson ve Spilka'nın elde ettikleri sonuca göre benlik değeri düşük olan bireyler Tanrı'yı cezalandıran, affetmeyen olarak algılama eğilimindedir.

Bu çalışmada bireylerin Tanrı algılarını belirlemek için bir ölçek geliştirmek amaçlanmıştır. Geliştirilmek istenen bu ölçekle iki tip Tanrı algısı yönelimini ölçmek hedeflenmiştir. Bunlar "sevgi yönelimli Tanrı algısı" ve "korku yönelimli Tanrı algısı" olarak isimlendirilmişlerdir. Tanrı'ya yönelik olumlu atıflar, Tanrı'nın çok seven, koruyan, şefkatli, affedici gibi özelliklerle algılanmasıdır. Olumlu bir Tanrı algısı olan birey aynı zamanda Tanrı'ya karşı da olumlu ve sevgi yönelimli bir tutum sergilemektedir. Bu yönde atıfları baskın olan bireylerin Tanrı algılarının sevgi yönelimli olduğu söylenebilir. Cezalandıran, korkutan, gaddar gibi yüklemeler de Tanrı'ya yönelik olumsuz atıflardır. Bu atıfları baskın olan bireylerin Tanrı algıları korku yönelimlidir denebilir.

2 Yapıcı, A.; (1996). Dini Yaşayışta Tövbeye Din Psikolojik Bir Yaklaşım, Yayımlanmamış Yüksek Lisans Tezi, Kayseri.

3 Benson, P., Spilka, B., (1973), "God Image as a Function of Self-Esteem and Locus of Control", Journal for the Scientific Study of Religion, Vol. 12, No: 3, September, sf: 297-310.

4 Cecero, J.,J.; Marmon, T.,S.; Beitel, M.; Hutz, A. Ve Jones, C.; (2004). Images of Mother, Self, and God as Predictors of Dysphoria in Non- Clinical Samples, Personality and Individual Differences, 36: 1669- 1680. 


\section{Tanrı Korkusu ve Tanrı Sevgisi}

Sevgi ve korku insanın temel ve gerekli duygularındandır. Sevgi, yaşamına anlam katarken, korku hayatta kalmasına yardımcı olur. Ancak sevgi içinde korkuyu barındıramaz. Tanrı'ya ilişkin olarak bu duygulara baktığımızda her iki duygunun da dini öğreti içerisinde yer aldığını, hemen her inananın bu duyguları zaman zaman deneyimlediğini görürüz.

Tanrı korkusu, kutsalın korkutucu olarak düşünülmesi sonucunda doğabilir. Kutsal bilinmezlikler içerir; bu da bireyin ondan korkması ve kendi acizliğini görmesine neden olur. Hem kutsalın kendi büyüklüğü ve gücü hem de insanın sınırlılıkları ve güçsüzlüğü bu korkuya neden olmaktadır. ${ }^{5}$ Dini öğretilere göre, suçlu insan Tanrı tarafından yargılanacağı için korku ortaya çıabilir. İnsan mutlaka hata yapar. Bu nedenle de Tanrı'nın cezalandırıcı özelliklerine odaklanmış olan birey Tanrı'nın azabından korkmaktadir.

Tanrı sevgisi, kişiyi Tanrı'ya yaklaşmaya ve bağlanmaya yönlendirir. Bireyin Tanrı ile ilgili bildikleri ve bunların bilincinde olması ile O'na yönelik duygusal yönelimi şekillenmektedir. Tanrı'nın çok seven (Rahman) ve şefkatli olduğu bilgisi ve derin farkındalığına sahip olan bireyin, sevgi yönelimli Tanrı algısına sahip olması beklenebilir.

Ergenlik döneminin, dini kişiliğin kazanılmasında çok önemli olduğunu ifade edilir ${ }^{6}$. Çocukluk ve ergenlikte sevgi ve ilgiden yoksun olma, dini inanç ve tutumlarda bazı olumsuzluklara ve sapmalara neden olmaktadır. Albayrak'ın yaptığı araştırmaya göre ailede ve okulda baskı ve korkuya dayalı bir din eğitimi alan ergenlerde, korkuya dayalı olumsuz dini inanç ve tutumlar ortaya çıkmıştır. Sevgi motifi Tanrı'ya yaklaşmada daha etkili olmuştur.

Bacanlı tarafından yapılan bir araştırmada ${ }^{7}$, Konya Selçuk Üniversitesi'nden araştırmaya katılan 77 öğrencinin Tanrı ile ilgili sıfatlara verdikleri cevaplara göre; tüm deneklerin işaretlediği sıfat "Affedici"; işaretlenme sıklı̆̆ 1 en çok olan ikinci sıfat "Yaratıcı", üçüncüsü ise kızlarda "Güvenilir" erkeklerde ise "Güçlü" şıkları olmuştur. Deneklerin tümünün işaretlediği tek sıfat "Affedici" sıfatıdır. Bununla birlikte, araştırmada deneklerin hiçbiri cezalandırıcı sıfatlarını işaretlememiştir. Araştırmacı denekleri, Tanrı'yı 'korkulan' değil ‘sevilen' olarak algıladıkları yönünde değerlendirmiştir.

5 Yapıcı, A.; (1996). Dini Yaşayışta Tövbeye Din Psikolojik Bir Yaklaşım, Yayımlanmamış Yüksek Lisans Tezi, Kayseri.

6 Albayrak, A.; (1995). Ergenlerin Dini Gelişiminde Sevgi ve Korku Motifinin Etkinliği, Yayımlanmamış Yüksek Lisans Tezi, Uludağ Üniversitesi Sosyal Bilimler Enstitüsü, Bursa.

7 Bacanlı, H.; (1995). Tanrı ve Peygamber Kavramları, Din Eğitimi Araștırmaları Dergisi, 2, 155163; Akt: Bacanlı, H.; (2002). Psikolojik Kavram Analizleri, Nobel Yayın Dağıtım, Ankara. 
Hıristiyan üniversite öğrencileri üzerinde yapılan bir çalışmada ${ }^{8}$ gençlerin Tanrı kavramları çeşitli değişkenlere göre incelenmiş; "Uzak- mesafeli bir Tanrı" ve "İntikam alan bir Tanrı" algıları ile akademik alan yüksek bir ilişki göstermiştir. "İlgisiz bir Tanrı", "Görkemli bir Tanrı" ve " İntikam alan bir Tanrı" algıları ile de cinsiyet yüksek korelasyon göstermiştir. Buna göre kadınlar, erkeklere göre, Tanrı'yı daha "dikkat çekici", "saygın" ve "saygıyla karışık bir korkuya neden olan" olarak görmekte ve erkeklerden daha az "cezalandırıcı" olarak tanımlamaktadır. Kadınlar, Tanrı'ya yönelik olumsuz atıfta bulunmaya karşı daha isteksiz olmuşlardır. "İyilik sever", "Yaratıc1", "Görkemli", "Güçlü", "Tensel” ve "Değerli" Tanrı kavramlarına en çok katılan bireyler daha derin bir inanca sahipken, daha az katılanlar derin inanca sahip çıkmamışırı. "İntikam Güden" Tanrı algısı ile derin inanç arasında bir ilişki bulunamamıştır.

Bu çalışmanın amacı bireylerin Tanrı algılarını ölçecek bir ölçek geliştirmektir. Tanrı algısı konusunda yapılacak çeşitli araştırmalara imkan sağlaması için bu ölçeğin uygun bir veri toplama aracı olması amaçlanmıştır.

\section{B. YÖNTEM}

\section{Örneklem}

Araştırmanın örneklemini 20-60 yaş arasındaki 535 yetişkin birey oluşturmuştur. Örneklem seçkisiz olarak Bursa, Ankara, Erzincan, Samsun, İstanbul ve Mersin (Silifke) illerinden oluşturulmuştur. Katılımcıların 272'si erkek ve 263'ü kadındır. Tüm grubun yaş ortalaması 34 tür.

Tablo 1. Örneklemin yaş, cinsiyet ve eğitim durumları

\begin{tabular}{|ll|c|c|}
\hline \multirow{2}{*}{ EĞİTiM } & & \multicolumn{2}{|c|}{ CINSIYYT } \\
\cline { 3 - 4 } & & ERKEK & KADIN \\
\hline \multirow{2}{*}{ İLK } & Erken & 13 & 13 \\
& Yetişkin & 17 & 21 \\
LisE & Orta Yaş & & 55 \\
& Erken & 55 & 28 \\
\multirow{2}{*}{ LíSANS ve ÜSTÜ } & Yetişkin & 30 & 111 \\
& Orta Yaş & & 35 \\
& Erken & 120 & \\
\hline
\end{tabular}

8 Hammersla, J.,F.; Andrews- Qualls, L.,C.\& Frease, L.,G.; (1986). God Concepts and Religious Commitment Among Christian University Students, Journal for the Scientific Study of Religion, 25(4): 424-435. 


\section{Veri Toplama Araçları}

Tanrı Algısı Soru Formu: Araştırmada, araştırmacı tarafından hazırlanan 32 maddelik Tanrı Algısı Soru Formu kullanılmıştır. Form 5li Likert tipi olarak hazırlanmıştır. Formu oluşturan soruların yarısı Seven ve Affedici Tanrı'yı; yarısı da Cezalandıran Tanrı'yı niteleyen maddelerden oluşmuştur. Form maddeleri oluşturulurken seçkisiz olarak belirlenen bireylere Tanrı algıları sorulmuş ve bu konuda bir kompozisyon yazmaları istenmiştir. İlgili literatür incelenerek ölçek ifadeleri yazılmış ve form 32 madde ile analize hazır hale getirilmiştir.

Ölçek maddeleri hazırlanırken Tanrı algısı olumlu ve olumsuz olarak ikiye ayrılmış, bu boyutları belirlemede de iki tip yönelim belirlenmiştir. Bunlar Tanrı'ya sevgi yönelimi ve korku yönelimidir. Korku yönelimli Tanrı algısında "Cezalandıran, Affetmeyen, Uzak, Korkutucu Tanrı ile ilgili ifadeler; sevgi yönelimli Tanrı algısında ise "Affeden, Şefkatli, Çok Seven, Güvenilir Tanrı" ile ilgili ifadeler ölçek maddelerini meydana getirmiştir. Ölçekteki ifadelerin bu yönelimleri karşıladığını sınamak için konusunda uzman olan akademisyenlerden her bir ifadenin hangi yönelimi (Sevgi X Korku) ölçtüğünü belirtmeleri istenmiş; tüm yorumlar göz önüne alınarak ölçeğin geçerlik analizi gerçekleştirilmiştir.

Ölçek maddeleri 5'li Likert tipi ve ölçeğin yönergesi ve basımı buna uygun olarak hazırlanmıştır. Ölçeğin yönergesi şu şekildedir: Değerli katılımcılar. Aşağıda "Allah" hakkındaki duygu, düşünce ve davranışlarınıza ilişkin ifadeler bulunmaktadır. Sizden istenen, her bir ifadeyi dikkatlice okuyup, ifadenin sizi ne kadar yansittığını, karşısında bulunan derecelendirilmiş kutucuklara işaretlemenizdir. Araştırmadan sağlıklı ve doğru bilgiler elde edilebilmesi için lütfen çekinmeden gerçek fikirlerinizi belirtmeye çalışın. Derecelendirme, "Hiç Yansıtmıyor" (1), "Kısmen Yansitıyor" (2), "Biraz Yansıtıyor" (3), "Oldukça Yansitıyor" (4) ve "Tamamen Yansitıyor" (5) şeklinde yapılmakta ve puanlanmaktadır. Puanlardaki yükselme olumlu (sevgi yönelimli) bir Tanrı algısını göstermektedir.

Günahkarlık Duygusu Ölçeği (GDÖ): Araştırma da ayrıca Ö. Güler tarafından geliştirilen Günahkarlık Duygusu Ölçeği (GDÖ) de kullanılmıştır. 5'li Likert tipi 20 maddeden oluşan ölçek bireylerin günahkarlık duygularını ölçmektedir. Ölçekten alınan yüksek puanlar yıkıcı bir günahkarlık duygusunu göstermektedir. Ölçeğin değerlendirildiği ilk çalışmada9 Cronbach

9 Güler, Ö.; (2006). Günahkarlık Duygusu Ölçeği: Ölçek Geliştirme, Geçerlik ve Güvenirlik Çalışması, Yayınlanmamış Çalışma. 
alpha güvenirlik katsayısı,90 (N:512), kullanıldığı başka bir çalışmada ${ }^{10}, 92$ (N:536) olarak bulunmuştur. Ölçek üç faktörden oluşmuştur. "Aşırı Pişmanlık, Kendini Cezalandırma ve Ceza Beklentisi” faktörlerini ölçmektedir.

Kisa Semptom Envanteri (KSE): Özgün adı Brief Symptom Inventory (BSI) olan ve L. R. Derogatis (1992) tarafindan geliştirilen Kısa Semptom Envanteri (KSE) N. H. Şahin ve A. Durak (1994) tarafından Türkçe'ye uyarlanmıştır. Verilen cevaplara 0 ile 4 arasında değişen puanlar verilir. Puan ranjı 0- 212 dir. Ölçekten alınan toplam puanların yüksekliği, bireyin semptomlarının sıklığını gösterir. Üç ayrı çalışmada ölçeğin toplam puanından elde edilen Cronbach Alpha iç tutarlık katsayıları .96 ve .95 arasında değişmektedir. Yapılan faktör analizinde ölçeğin anksiyete, depresyon, olumsuz benlik, somatizasyon ve hostilite olarak beş faktörden oluştuğu bulunmuş$\operatorname{tur}^{11}$.

işlem

Ölçek hem gruplar halinde hem de bireylere 3 aylık bir sürede uygulanmıştır. Uygulamayı bireyler tek başlarına, kendileri yapmışlardır. Araştırmada toplanan veriler SPSS 11.0 istatistik paket programı yardımı ile araştırmac1 tarafından analiz edilmiştir.

\section{BULGULAR}

İlk olarak madde analizi yapılması ve işler maddelerin belirlenmesi için madde toplam puan korelasyonlarına bakılmıştır. Ölçekte bulunan maddelerin madde toplam puan korelasyonları Tablo 2'de verilmiştir. Korelasyonlar incelendiğinde 20 ve 22 nolu maddeler ölçek toplamı ile p<,01 düzeyinde anlamlı ilişki göstermemiştir. Korelasyonu .30'un altında kalan maddeler de (1., 10. ve 32.) ölçekten çıkarılmıştır.

Ölçek konularında uzman olan akademisyenlere gönderilmiş ve ifadelerin hedeflenen boyutları ölçüp ölçmediğini belirlemeleri istenmiştir. Toplanan verilerin analizi sonucunda 1., 23., 28., 29. ve 30. ifadelerde fikir birliği sağlanamadığı görülerek ölçekten çıkarılmıştır.

Üçüncü olarak, araştırma örnekleminin KSE puan ortalaması hesaplanarak $(X=45,48, S s=36,78)$ araştırma örnekleminin içerisinde yer alan yetişkinler Kısa Semptom Envanteri'nden aldıkları puanlara göre iki uç gruba ayrılmıştır. Ortalamanın bir Ss üstü 82,26; bir standart sapma altı 8,7

10 Güler, Ö.; (2007). Tanrı' ya Yönelik Atıflar, Benlik Algısı ve Günahkarlık Duygusu, Yayınlanmamıș Yüksek Lisans Tezi, Ankara Üniversitesi Sosyal Bilimler Enstitüsü, Ankara.

11 Savaşır, I. Ve Şahin, N.; (1997). Bilişsel ve Davranışçı Terapilerde Değerlendirme: Sık Kullanılan Ölçekler, TPD Yay., Ankara 
Tablo 2. Madde Toplam Puan Korelasyonları

\begin{tabular}{|rl|ll|}
\hline \multicolumn{2}{|c|}{ TA Toplam } & \multicolumn{2}{|c|}{ TA Toplam } \\
\hline 1 &, $12^{* *}$ & 17 &, $42^{* *}$ \\
2 &, $32^{* *}$ & 18 &, $39 * *$ \\
3 &, $37^{* *}$ & 19 &, $42^{* *}$ \\
4 &, $34^{* *}$ & 20 &, $01^{* *}$ \\
5 &, $45^{* *}$ & 21 &, $49^{* *}$ \\
6 &, $45^{* *}$ & 22 &,$- 09^{* *}$ \\
7 &, $56^{* *}$ & 23 &, $51^{* *}$ \\
8 &, $44^{* *}$ & 24 &, $44^{* *}$ \\
9 &, $58^{* *}$ & 25 &, $37^{* *}$ \\
10 &, $25^{* *}$ & 26 &, $44^{* *}$ \\
11 &, $61^{* *}$ & 27 &, $48^{* *}$ \\
12 &, $39^{* *}$ & 28 &, $45^{* *}$ \\
13 &, $56^{* *}$ & 29 &, $32^{* *}$ \\
14 &, $38^{* *}$ & 30 &, $47^{* *}$ \\
15 &, $55^{* *}$ & 31 &, $49^{* *}$ \\
16 &, $34^{* *}$ & 32 &, $13^{* *}$ \\
\hline
\end{tabular}

$* \mathrm{r}<.30$ olan maddeler çıkartılmıştır.

$* * \mathrm{p}<.01$

olarak belirlenmiştir. KSE puanı $>82$ olanlar KSE yüksek grubunu ( $\mathrm{n}=88)$, KSE puan $<9$ olanlar KSE düşük grubunu $(n=67)$ oluşturmuştur. Deneklerin KSE'den en yüksek ve en düşük puanları almış iki grubun TA soru formuna verdikleri cevaplar $\mathrm{t}$ test ile karşılaştırılmıştır. $t$ test sonuçları Tablo 3 'te verilmiştir.

Tablo 3 'te görüldüğü gibi, 25. madde dışında, iki grup arasında anlamlı farklılığa sahip olan maddeler uzman görüşlerini desteklerken; 25. ifadeye daha fazla katılan grup semptomları yüksek olan grup olmuştur. Buna göre Tanrı'ya kavuşma isteği duyan bireylerin psikolojik semptomları yüksektir. Sevgi yönelimini karşıladığı düşünülen bu ifade psikolojik semptomları yüksek olan grupta çıktığı için işlevsel olmadığına karar verilmiş, bu nedenle 25. madde ölçekten çıkarılmıştır.

Sonuç olarak, soru formundan 10 madde $(1,10,20,22,23,25,28,29,30,32$ nolu maddeler) çıkartılmış, Tanrı algısı Ölçeği 22 madde ile hazır hale getirilmiştir. Yapılan güvenirlik analizi sonucunda 22 maddeden oluşan TA'nın Cronbach-alpha katsayısı,83 olarak bulunmuştur. 
Tablo 3. TA Formunun KSE Yüksek ve Düşük Gruba Göre t Testi Sonuçları

\begin{tabular}{|c|c|c|c|c|c|}
\hline \multirow[b]{2}{*}{ TA Maddeleri } & \multicolumn{2}{|c|}{$\begin{array}{c}\text { Semptomları } \\
\text { düşük grup } \\
\text { KSE }<9 \text { N:67 }\end{array}$} & \multicolumn{2}{|c|}{$\begin{array}{c}\text { Semptomları } \\
\text { yüksek grup } \\
\text { KSE }>82 \text { N:88 }\end{array}$} & \multirow[b]{2}{*}{$\mathrm{t}$} \\
\hline & $\mathrm{X}$ & Ss & $\mathrm{X}$ & Ss & \\
\hline $\begin{array}{l}\text { 1. O'nun sevgisini kaybetmekten } \\
\text { korkuyorum. }\end{array}$ & 3.13 & 1.73 & 2.14 & 1.42 & $87^{* *}$ \\
\hline $\begin{array}{l}\text { 2. O’nu düşünmek bana sıkıntı } \\
\text { veriyor. }\end{array}$ & 4.85 & .70 & 4.59 & .95 & $1.875 *$ \\
\hline $\begin{array}{l}\text { 4. O’nu düşündüğgümde utanıyorum } \\
\text { ve kendimi suçlu hissediyorum. }\end{array}$ & 4.05 & 1.41 & 2.82 & 1.60 & $4.97 * *$ \\
\hline $\begin{array}{l}\text { 6. O'nun bana karşı çok acımasız } \\
\text { olduğunu düşünüyorum. }\end{array}$ & 4.70 & .96 & 4.18 & 1.44 & $2.54^{*}$ \\
\hline $\begin{array}{l}\text { 10. O'nun gazabına uğramaktan } \\
\text { korkuyorum. }\end{array}$ & 2.86 & .71 & 2. & 4 & 2.9 \\
\hline 11. O'nun bana karşı çok merhametli & & & & & \\
\hline $\begin{array}{l}\text { olduğunu hissediyorum. } \\
\text { 12. O, yaptıklarım için beni }\end{array}$ & 4.41 & 1.07 & 3.93 & 1.34 & $2.42 *$ \\
\hline $\begin{array}{l}\text { cezalandırıyor. } \\
\text { 14. O'nun beni bağışlayacă̆ını }\end{array}$ & 4.02 & 1.42 & 3.27 & 1.37 & $3.34 *$ \\
\hline $\begin{array}{l}\text { zannetmiyorum. } \\
\text { 16. O'nu düşününce kendim için }\end{array}$ & 4.58 & 1.30 & 3.87 & 1.52 & $3.04 *$ \\
\hline $\begin{array}{l}\text { kaygılanıyorum. } \\
\text { 20. O, her an işlediğim günahlarımı }\end{array}$ & 4.13 & 1.39 & 2.64 & 1.42 & $6.50 * *$ \\
\hline $\begin{array}{l}\text { kaydediyor. } \\
\text { 22. O'nu düsündüğümde beni cezalan- }\end{array}$ & 2.05 & 1.63 & 1.53 & 1.08 & $2.40^{*}$ \\
\hline $\begin{array}{l}\text { 22. O'nu düşündüğümde beni cezalan- } \\
\text { dırmaması için O'ndan af diliyorum. } \\
\text { 24. O'nun bana yakın olduğunu }\end{array}$ & 2.16 & 1.61 & 1.59 & .99 & $2.73^{*}$ \\
\hline $\begin{array}{l}\text { sanmiyorum. } \\
\text { 25. O'nu düşündüğümde O’na }\end{array}$ & 4.52 & 1.21 & 3.77 & 1.77 & $-2.97 *$ \\
\hline $\begin{array}{l}\text { kavuşmayı arzuluyorum. } \\
\text { 26. O'nun zor zamanlarımda benim }\end{array}$ & 3.16 & 1.77 & 3.67 & 1.52 & $-1.90 *$ \\
\hline $\begin{array}{l}\text { yanımda olmadığını hissediyorum. } \\
\text { 28. O'nun bana adaletli davrandığını }\end{array}$ & 4.50 & 1.19 & 3.55 & 1.72 & $3.86^{* *}$ \\
\hline $\begin{array}{l}\text { sanmiyorum. } \\
\text { 29. O'nu düsününce kötülüklerimden }\end{array}$ & 4.79 & .74 & 4.25 & 1.34 & $2.95^{*}$ \\
\hline $\begin{array}{l}\text { arınmak için O'na tövbe ediyorum. } \\
\text { 30. O'nun benim dualarımı dinlediğini }\end{array}$ & 3.88 & 1.60 & 4.36 & 1.11 & $-2.20 *$ \\
\hline sanmiyorum. & 4.83 & .66 & 4.07 & 1.51 & $3.82 * *$ \\
\hline $\begin{array}{l}\text { 32. O'na itaat etmezsem cehenneme } \\
\text { gideceğimden korkuyorum. }\end{array}$ & 2.70 & 1.74 & 1.86 & 1.27 & $3.45^{* *}$ \\
\hline
\end{tabular}

$* \mathrm{p}<.05 * * \mathrm{p}<.001$ 


\section{Faktör Yapısı}

Yapılan faktör analizi sonucunda ölçeğin altı faktörden oluştuğu bulunmuştur. Elde edilen altı faktör, toplam varyansın \%55,6 sını açıklamaktadır.

Tablo 4. TA Faktör Analizi Sonuçları

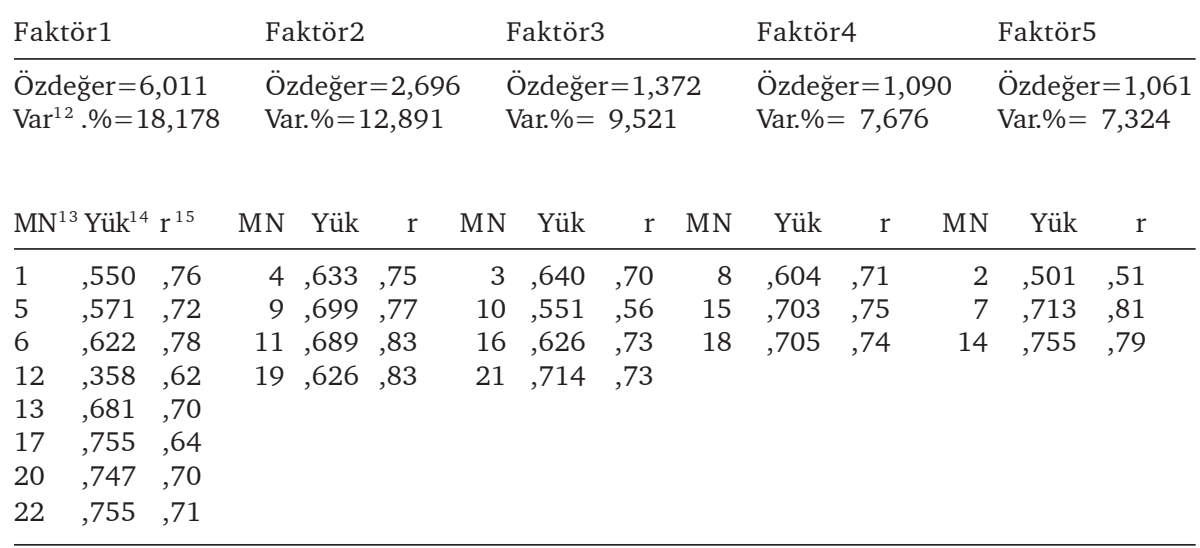

1. faktörün "Seven Tanrı", 2. faktörün "Tanrı'ya yönelik olumlu duygular", 3. faktörün "Uzak/ Umursamaz Tanrı", 4. faktörün "Korkutan ve cezalandıran Tanrı", 5. faktörün "Tanrı'ya yönelik olumsuz duygular" faktörlerini ölçtüğüne karar verilmiştir.

Ölçüt Bağıntılı Geçerlik: 22 maddelik TA'nın GDÖ ile korelasyonu -,24 $(\mathrm{p}<.01)$ negatif yönde anlamlı bir ilişki göstermiştir. Buna göre olumsuz Tanrı algısı olan bireylerin günahkarlık duygularının daha yüksek olduğu söylenebilir. 22 maddelik TA'nın KSE ile korelasyonu -21 $(\mathrm{p}<.01)$ negatif yönde anlamlı bir ilişki göstermiştir. Buna göre Tanrı algısı olumsuz olan bireylerin psikolojik semptomlarının daha fazla olduğu söylenebilir.

Puanlama: Ölçek maddeleri korku yönelimini ve sevgi yönelimini karş1layacak şekilde hazırlanmıştır. Sevgi ifadeleri düz puanlanırken, korku ifadeleri ters yönde puanlanmaktadır. Buna göre 1, 4, 5, 6, 9, 11, 12, 13, 17, 19,20 ve 22 numaralı ifadeler düz diğerleri ters puanlanmaktadır.

12 Var.= Döndürme sonrası açıklanan varyans yüzdesi

$13 \mathrm{MN}=$ Madde No

14 Yük= Döndürme sonrası yük değeri

$15 \mathrm{r}=$ Madde - altölçek toplam puan korelasyonu 


\section{SONUÇ VE DEĞERLENDIRME}

Tanrı algısı, inanan insanın yaşantısını, kendine ve dünyaya bakış açısını belirleyebileceği için çok önemlidir. Bireyin Tanrı ile olan ilişkisi çok hassas ve derin bir konudur. İnsanın mutluluğu, fiziksel ve ruhsal sağlığını etkilemektedir. Dinin öngördüğü huzur ve mutluluğu bu dünyada yaşamay1 arzulayan bireyin, sevgi öğelerine çok ihtiyaç duyduğu söylenebilir. Çünkü korku, insanı mutluluğun dışına iter. Bir dine sıkı sıkıya bağlanmış bireyin Tanrı'ya yönelik olumsuz, korku dolu algılarının onu mutlu edemeyeceği düşünülmektedir.

Bu çalışmada bireylerin Tanrı algılarını ölçmeyi amaçlayan bir ölçek geliştirilmiş̧ir. Olumlu ve olumsuz Tanrı algısını belirlemesi hedeflenen bu ölçek ile Tanrı'ya yönelik atıflar ile diğer pek çok değişken arasındaki ilişkileri incelemek mümkün olacaktır. Bu amaç doğrultusunda ölçek maddelerini belirlemek için bireylerden Tanrı ile ilgili duygu ve düşüncelerini yazmaları istenmiştir. İlgili literatür tarandıktan sonra ölçülmek istenen boyutlarla ilgili maddeler yazılmış ve 535 kişilik örnekleme uygulanmıştır. Ölçek maddelerinin belirlenen boyutları ölçüp ölçemediğinin belirlenmesi için konusunda uzman akademisyenlere tüm ifadeleri bu yönden değerlendirmeleri istenmiş ve ölçeğin kapsam geçerliği gerçekleştirilmiştir. Ayrıca form maddeleri Kısa Semptom Envanteri puanlarına göre de incelenmiştir. Uygulamada elde edilen verilerin analizi sonucunda 22 maddenin işler ve geçerli maddeler olduğu gözlenmiş ve ölçek bu ifadelerden oluşmuştur. Ölçeğin güvenirlik katsayısı .83 olarak bulunmuştur. Bu değer oldukça güvenilir bir ölçek olduğunu göstermektedir. Faktör yapısı incelendiğinde, ölçeğin beş faktörden oluştuğu bulunmuştur. Tüm faktörler toplam varyansın \% 55,6 sını açıklamıştır. Analizler sonucunda Tanrı Algısı Ölçeği (TA)'nin güvenilir ve geçerli bir ölçek olduğu görülmüştür.

\section{EK 1: Tanrı Algısı Ölçeği (TA)}

Değerli katılımcılar;

Aşağıda "Allah" hakkındaki duygu, düşünce ve davranışlarınıza ilişkin ifadeler bulunmaktadır. Sizden istenen; her bir ifadeyi dikkatlice okuyup, ifadenin sizi ne kadar yansıttığını, karşısında bulunan, derecelendirilmiş kutucuklara işaretlemenizdir. Araştırmadan sağlıklı ve doğru bilgiler elde edilebilmesi için lütfen çekinmeden gerçek fikirlerinizi belirtmeye çalışın. 


\begin{tabular}{|c|c|c|c|c|c|c|}
\hline \multicolumn{2}{|r|}{ İ F A D E } & \multirow{2}{*}{$\frac{\text { 垈 }}{1}$} & \multirow{2}{*}{ 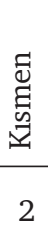 } & \multirow{2}{*}{$\frac{\underset{\mathscr{D}}{\mathscr{\oplus}}}{3}$} & \multirow{2}{*}{ 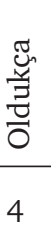 } & \multirow{2}{*}{ 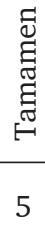 } \\
\hline 1 & O'nun bana karşı çok merhametli olduğunu hissediyorum. & & & & & \\
\hline 2 & O'nu düşünmek bana sıkıntı veriyor. & 1 & 2 & 3 & 4 & 5 \\
\hline 3 & O'nun beni bağışlayacağını zannetmiyorum. & 1 & 2 & 3 & 4 & 5 \\
\hline 4 & O'nu düşündüğg̈̈mde içimden gelen tek duygu: sevgi. & 1 & 2 & 3 & 4 & 5 \\
\hline 5 & O'nun bana olan sevgisini hissedebiliyorum. & 1 & 2 & 3 & 4 & 5 \\
\hline 6 & O'nun bana şefkatle davrandığını hissedebiliyorum. & 1 & 2 & 3 & 4 & 5 \\
\hline 7 & $\begin{array}{l}\text { O'nu düşündüğümde utanıyorum ve kendimi suçlu } \\
\text { hissediyorum. }\end{array}$ & 1 & 2 & 3 & 4 & 5 \\
\hline 8 & O'nun bana karşı çok acımasız olduğunu düşünüyorum. & 1 & 2 & 3 & 4 & 5 \\
\hline 9 & O'nu düşünmek bana güven veriyor. & 1 & 2 & 3 & 4 & 5 \\
\hline 10 & O aklıma geldiğinde O'ndan kaçıp uzaklaşmak istiyorum. & 1 & 2 & 3 & 4 & 5 \\
\hline 11 & O'nu düşünmek beni mutlu ediyor ve içim sevinçle doluyor. & 1 & 2 & 3 & 4 & 5 \\
\hline 12 & O, ne yaparsam yapayım kusurlarımı örtüyor. & 1 & 2 & 3 & 4 & 5 \\
\hline 13 & O, her zaman güvenebileceğim tek kaynaktır. & 1 & 2 & 3 & 4 & 5 \\
\hline 14 & O'nu düşününce kendim için kaygılanıyorum. & 1 & 2 & 3 & 4 & 5 \\
\hline 15 & O, benim için korkutucudur. & 1 & 2 & 3 & 4 & 5 \\
\hline 16 & $\begin{array}{l}\text { Zor zamanlarımda, O’nun, yanımda olmadığını } \\
\text { hissediyorum. }\end{array}$ & 1 & 2 & 3 & 4 & 5 \\
\hline 17 & O, bütün insanları karşılık beklemeden sever. & 1 & 2 & 3 & 4 & 5 \\
\hline 18 & O, yaptıklarım için beni cezalandırıyor. & 1 & 2 & 3 & 4 & 5 \\
\hline 19 & O'nu düşünmekle huzur buluyorum. & 1 & 2 & 3 & 4 & 5 \\
\hline 20 & O, bence gerçekten de çok bağışlayıcıdır. & 1 & 2 & 3 & 4 & 5 \\
\hline 21 & O'nun bana yakın olduğunu sanmıyorum. & 1 & 2 & 3 & 4 & 5 \\
\hline 22 & O'nun beni her durumda koruduğunu biliyorum. & 1 & 2 & 3 & 4 & 5 \\
\hline
\end{tabular}

Yazar Notu:

Prof. Dr. Sn. Nesrin Hisli Şahin, Prof. Dr. Sn. Hayati Hökelekli, Prof. Dr. Sn. Salih Akdemir, Doç. Dr. Sn. Hasan Kayıklık, Doç. Dr. Sn. Öznur Özdoğan, Yrd. Doç. Dr. Sn. Abdulkerim Bahadır, Yrd. Doç. Dr. Sn. Abdülvahit İmamoğlu, Yrd. Doç. Dr. Sn. Ersin Kuşdil, Yrd. Doç. Dr. Sn. Halil Apaydın, Yrd. Doç. Dr. Sn. Naci Kula, Dr. Sn. Gülay Dirik, Dr. Sn. Hasan Kaplan'a değerli katkılarından dolayı teşekkür ederim. 